\title{
Measurement of Turbulent Flame Speed of Natural Gas/Air Mixtures at Elevated Pressure
}

\author{
$\mathrm{Li} \mathrm{Li}^{*} \& \mathrm{~J} \mathrm{~J}$ Witton ${ }^{2}$
}

\begin{abstract}
Turbulent flame speeds were measured over a range of pressures to $0.8 \mathrm{MPa}$ using a jet-flow apparatus fired with a synthetic mixture representing a mid-European natural gas. The equivalence ratio (Ø) was 0.9. The gas contained significant proportions of ballast gases and higher hydrocarbons.

The method adopted was the 'flame angle' technique, using schlieren imaging to obtain the flame vertex angle from the peak density gradient. Image analysis techniques were developed to reduce interpretation errors and give an unbiased result. The data shows higher flame speeds than were obtained with pure methane at elevated pressures, using similar methodology, and has an application in numerical modelling of combustors.
\end{abstract}

Key words: Combustion; Fuels; Flame speed; Numerical modelling.

${ }^{*}$ RWE NPower Company, formerly Combustor \& Heat Transfer Technology Group, School of Engineering, Cranfield University, li.li@ rwenpower.com, Corresponding author.

${ }^{2}$ Combustor \& Heat Transfer Technology Group, School of Engineering, Cranfield University, Bedford, MK43 0AL, j.j.witton@cranfield.ac.uk

\section{NOMENCLATURE}

Da Damköhler number

Ka Karlovitz number

It Integral length scale

$\mathrm{P} \quad$ Mixture pressure

$\mathrm{Re}_{\mathrm{T}} \quad$ Nozzle Reynolds number

V Nozzle velocity

$\mathrm{S}_{\mathrm{L}} \quad$ Laminar flame speed

$\mathrm{S}_{\mathrm{T}} \quad$ Turbulent flame speed

$\mathrm{T} \quad$ Mixture temperature

u' Fluctuating velocity

\section{Greek Letters}

$\delta \quad$ Flame thickness

$\lambda \quad$ Taylor scale

$\eta \quad$ Kolmogoroff scale 


\section{Introduction}

For advanced GT Combustion Systems, the high efficiency, low pollutant emission and stabilization of the lean flame in the engine are more and more required. A database for turbulent flame properties is needed both for practical uses and developing multi-dimensional models for numerical simulations. Unfortunately still only few experimental studies are available for detailed high pressure premixed turbulent flame, especially under different temperature and fuels. Kobayashi et al. [1-2] used a Bunsen burner with perforated plates within a constant pressure chamber operated up to 3.0 MPa. His schlieren images showed finer turbulence structures in high pressure environments than at low pressure. Soika et al.[3] used a bluff body stabilized flame up to 1.1 MPa. They indicated the effect on the smaller turbulence scale and flame instabilities by pressure. Lachaux et al.[4] studied lean premixed $(\varnothing=0.6)$ flames up to 0.9 MPa using a Bunsen burner. They studied the wrinkling scales, flame front curvature and surface density by using LDA and Mie scattering tomography. They showed that the increased pressure can cause small scale flame structures but roughly constant integral length scales.

In the present study, we use a synthetic gas mixture, designated "Ruhr Gas", typical of compositions used in mid-Europe, which contains significant amounts of ballast and higher hydrocarbons. The turbulent flame velocity measurements were taken under different pressures and temperatures.

\section{Experimental Hardware Design \& Construction}

A turbulent flame speed experiment with a jet-stabilized pre-mixed flame having optical access for LDA and schlieren analysis was constructed. The design of the jet nozzle and its velocity and turbulence profiles was explored using CFD (FLUENT) and checked by cold experiment. The criteria of primary importance for the nozzle flow are taken as uniform mean and turbulent velocity and mixture concentration distributions at the jet exit, with steep wall gradients. The maximum sustainable grid-induced turbulence levels are about $8 \%$ from an area contraction ratio of 7.29 , with third-order wall profile and a nozzle exit diameter of $20 \mathrm{~mm}$ : the intrinsic, clean jet turbulence is $\sim 1.5 \%$. Flame stabilization was provided by a thin rim, the outer face of which formed the inner annulus of the flame root stabilization diffusion flame fuel supply. The outer wall of the diffusion flame flow-path was heavily cooled by radiation to a water jacket: the diffusion flame fuel was not pre-heated.

To reduce risk and experimental tuning of apparatus to a minimum, CFD simulation was used to guide the design of the flow-path of the experiment, in particular for the jet nozzle profile and turbulence generator, and for a heat transfer study of the high-pressure casing and optical windows. The tasks were broken down into nozzle and turbulence generator studies, combustion chamber flow and heat transfer.

Preparation of a homogeneous pre-mixed fuel: air mixture close to the point of use has difficulties and contradictory requirements, given the relative fuel and air mass and momentum ratios available and the final range of nozzle exit velocity. It was decided to pre-mix the fuel and air upstream of the nozzle and control the wall boundary layer growth to minimize flashback propensity and produce a well-controlled shear layer with the stabilization flow.

\subsection{Jet Nozzle \& Turbulence Generator}

The mean flow and mixture concentration fields at the nozzle exit must be controllable, symmetrical and, ideally, flat, with similar characteristics over a range of nozzle Reynolds Number. A conventional round jet with exchangeable turbulence generator plates was used to enable 
turbulence levels to be varied. To minimize the possibilities of flashback during combustion, the wall boundary layer should be thin and continuous, with the highest level of induced turbulence sustainable and the lowest intrinsic (i.e. clean) turbulence level in the core flow for each case. The conventional method of using an accelerated flow to achieve low intrinsic turbulence has the risk that any flashback of the flame may propagate into a large space holding combustible mixture. A study of the contraction area ratio, wall profile and exit velocity distribution showed that a thirdorder wall profile and AR of $\sim 8$ would produce the required mean flow field.

The turbulence generator flow should be sufficiently mixed prior to the exit plane to minimize the opportunity for aerodynamic flame-holding. Surveying flow conditioner design showed that the simple perforated grid-plate design represented a solution [5], enabling simple tuning using the orifice area and few restrictions on manufacture. A numerical study was run to indicate the optimum grid-plate porosity and hole size, with hole spacing, radial and circumferential, adjusted.
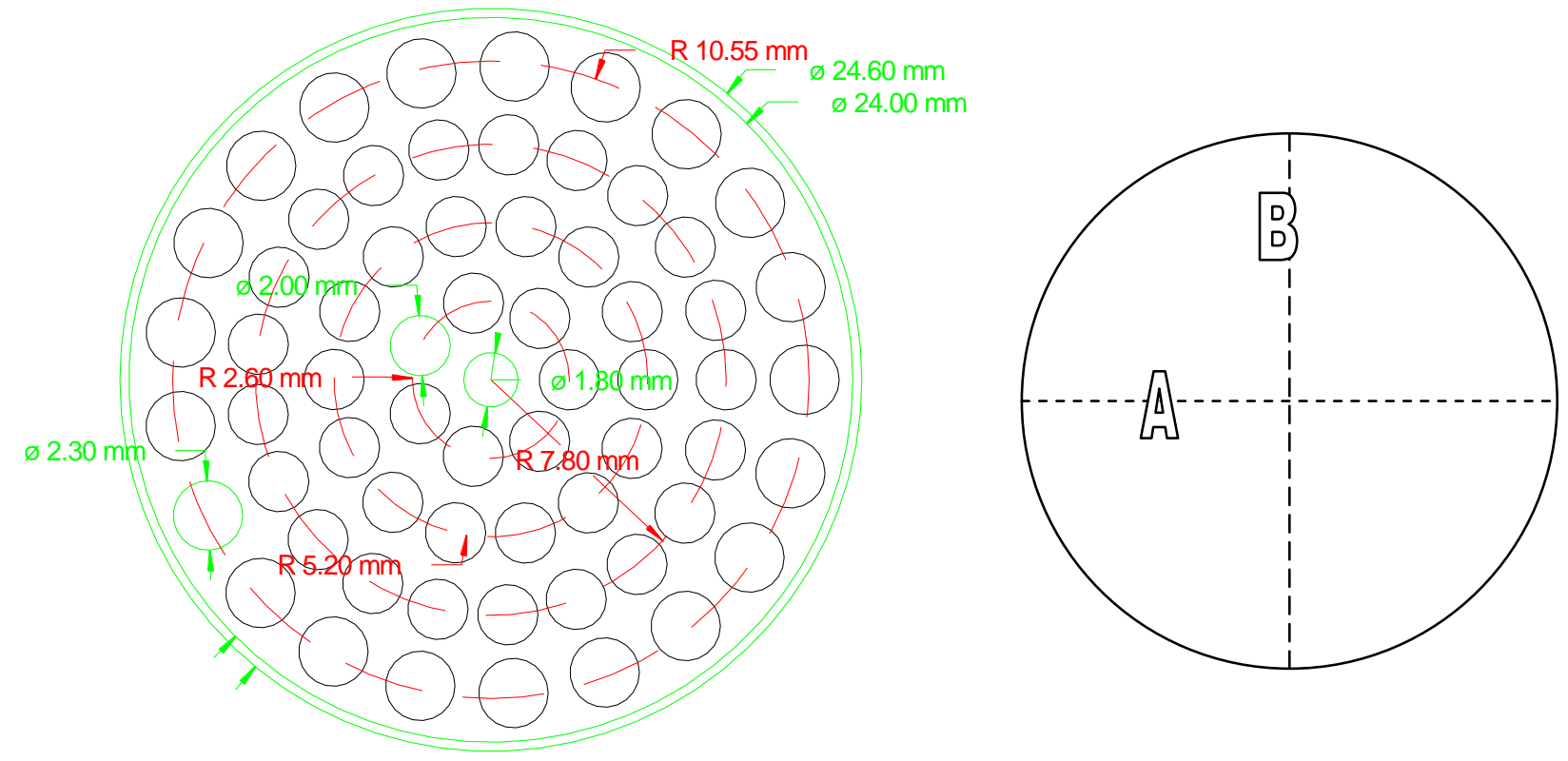

Fig. 1 The turbulence generation plate and Test lines

The test for the velocity and turbulence intensity:
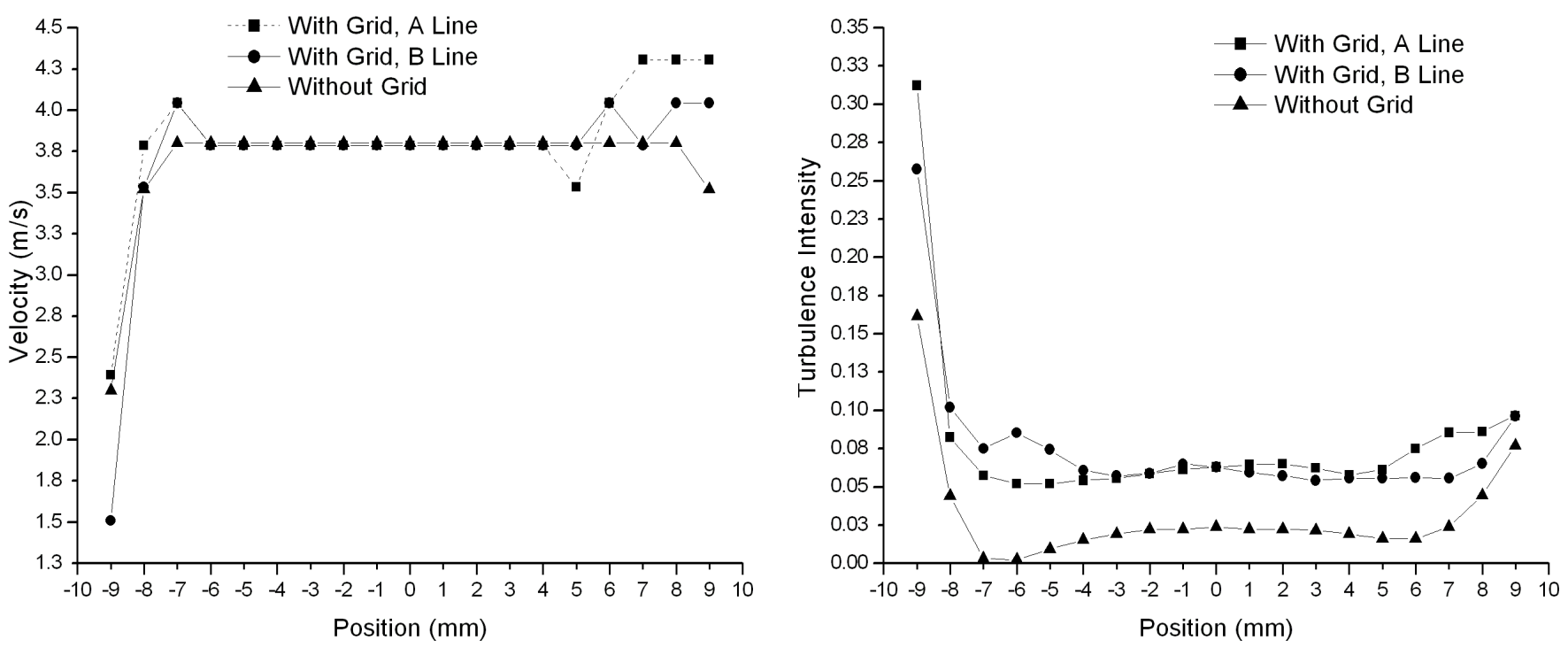

Fig. 2 Velocity \& Turbulence distribution 


\subsection{Performance Check of the Nozzle, Turbulence Generator \& Mixer}

Detailed construction of the components required close-tolerance CNC machining of many mating parts forming the final assembly. The assemblies were made in stainless steel and copper and vacuum-brazed together. Before committing to this step, the CNC programmes and fluid dynamic performance of the designs were checked using aluminium models at full-size, run with air at the operating nozzle Reynolds Number range expected in the combustion experiments. Mean and fluctuating velocity in the jet was measured using HWA. In the case of the mixer, helium was used as a tracer, with a mass spectrometer to map concentration fields across the nozzle exhaust plane.

\subsection{Pressure Casing and Internal Combustion Liner}

A twin-wall, convectively cooled inner liner was taken as the basic design. The casing was fabricated from carbon steel to standard pressure vessel design codes and standards. Provision for four windows aligned on two orthogonal, axially off-set diameters was made: the windows were made of laser-quality fused quartz glass, resiliently mounted in a frame that formed the cooling and ventilation gallery for window purge. Blanks were made for the window apertures not used. Provision was made to move the nozzle vertically with respect to the window axis to enable variations in flame location to be accommodated without major re-alignment of the optical axis.

The internal double-skinned stainless steel combustion liner was insulated with a high-grade material and wall film-cooled. The inside was painted with matt black high-temperature paint to minimize reflection.

Heat transfer analysis was performed for the high pressure containment. The concerns are that for the size of jet and its heat release, the wall thermal losses could appreciably alter the quasi-adiabatic boundary condition of the practical gas turbine combustor flames for which model data is sought, and the thermal loading and stressing of the optical windows. The casing for the experiment is then a compromise between size (mass and pressure capability) and modification to the jet flow (chamber diameter/volume) and the relative energy input. At the maximum condition for which data was sought, the maximum heat release from the jet flame was $\sim 36 \mathrm{~kW}$. The solution applied used a separate internal insulated liner to limit radial and axial heat loss. This was contained in a lightgauge metallic structure to approximate a realistic radiative boundary. The pressure vessel had some relatively large apertures necessary for windows with views across and oblique to the jet axis to permit optical measurements. The thermal losses from the windows could not be compensated but those windows not used for any set of measurements were covered with appropriately constructed blanks.

\subsection{The Schlieren System}

Most premixed turbulent flames of practical interest are within the flamelet regime. Thin flamelets also mean that the flame zone is characterized by large density gradients. This offers high sensitivity to the application of light deflection techniques such as schlieren, deflection mapping and interferometry. A typical flamelet oriented parallel to the incident beam direction produces a density gradient orthogonal to the beam and because schlieren is only sensitive to density gradients orthogonal to the beam, flamelets normal to the beam direction will be transparent. For the conical flame configuration, schlieren can outline the flame cone very clearly [6].

The optical system was built around a folded-path arrangement using large spherical mirrors, diameter $305 \mathrm{~mm}$, to reduce distortion. Images were generated using a Xenon flash lamp source (100hz repetition rate, $60 \mathrm{w}$ average input, $2.90 \mathrm{us}$ average flash duration) driven by a signal generator and CCD camera $(1024 \times 1260$ resolution) to capture the images. Image files were 
dumped directly to a PC hard drive. The window apertures were $100 \mathrm{~mm}$ and the whole window area could be imaged.

\subsection{Experiment Control System}

The main features are shown schematically below. Thermal mass-flow meters/controllers were used for air and fuel feed. These were check-calibrated at intervals throughout the experiments. Rig pressure was maintained by an exhaust regulating valve or fixed orifice, depending on need. Coolant was supplied to the jet nozzle jacket under manual control. Spark ignition, driven by a conventional HV transformer, was used with a retractable electrode.
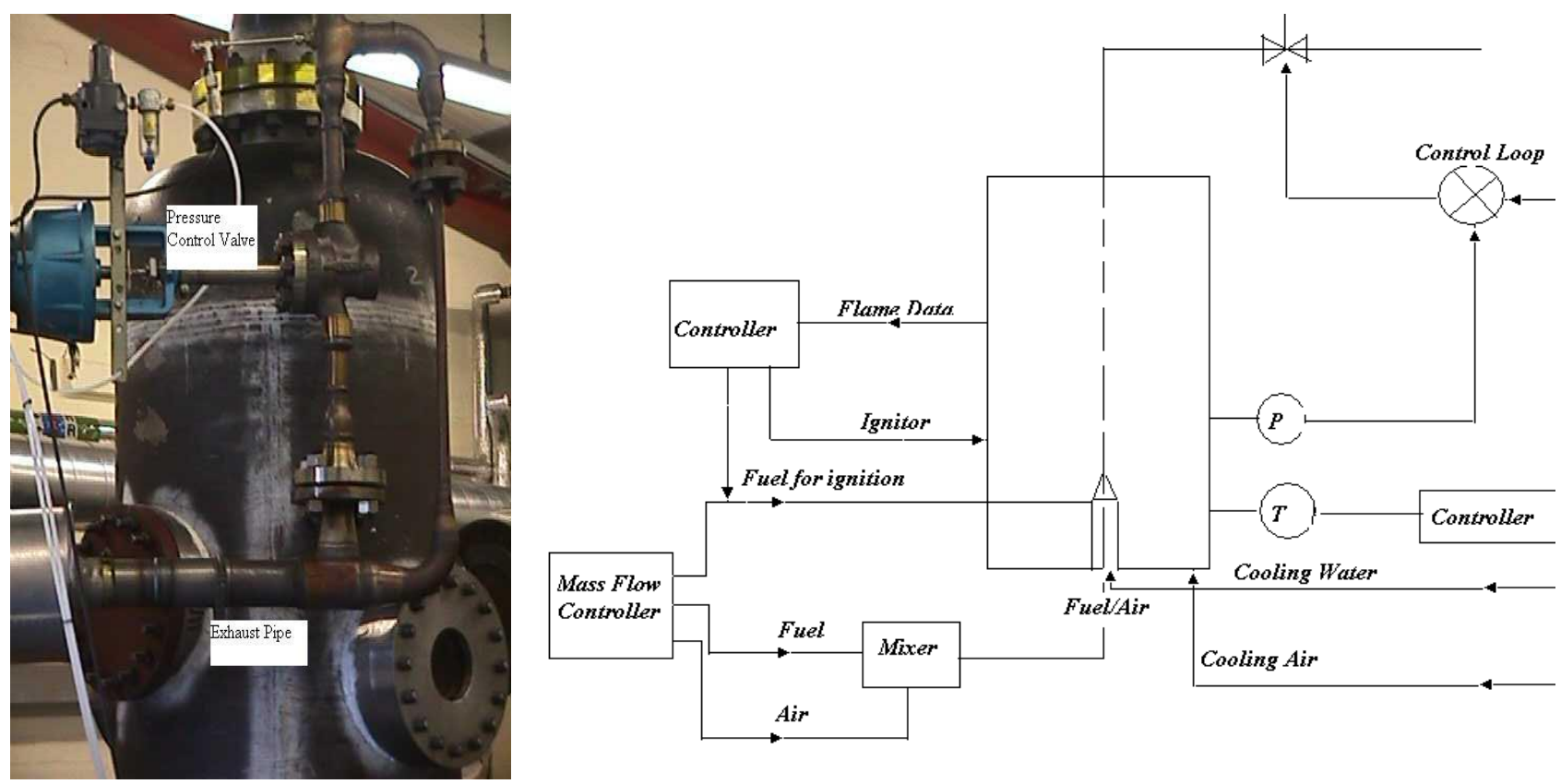

Fig. 3 Overview of the experimental rig

Data was acquired from digital pressure transducers, the mass-flow controllers and thermocouples and logged to PC using standard methods. Some on-line data reduction enabled the operator to control rig health, safety and set-point conditions.

\section{Results}

The flame speed is determined by the angle method $\left(\mathrm{S}_{\mathrm{T}}=\mathrm{U} \sin (\theta / 2)\right.$, where $\mathrm{U}$ is the mean velocity of mixture at the tube outlet, $\theta$ is the vertex angle of the mean flame region).

The initial testing phase established a stable flame and consistent conditions. Flame root stabilization was provided using the test fuel, although the apparatus would burn without diffusion support over a reasonable equivalence ratio at room temperature. All the data presented is with root stabilization, for consistency.

At elevated pressure, the flame brush became shorter and less well-defined, with the degree of definition becoming less as the nozzle Reynolds Number was increased. It was possible to reduce the pilot stabilization flow to a small value. The illustration shows typical results on the test fuel. 


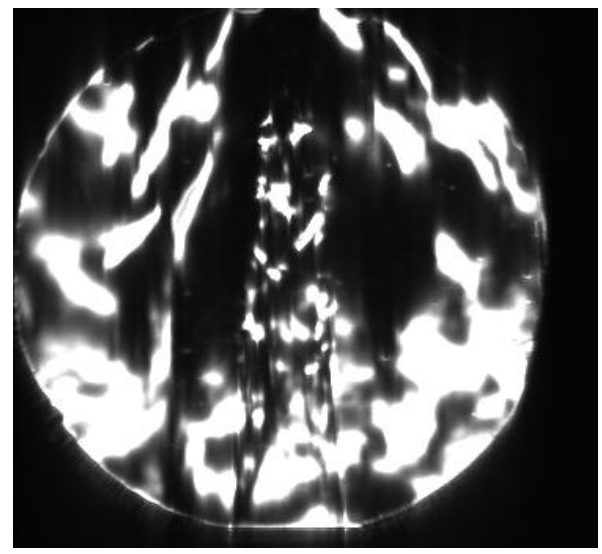

$\mathrm{P}=0.1 \mathrm{MPa}$

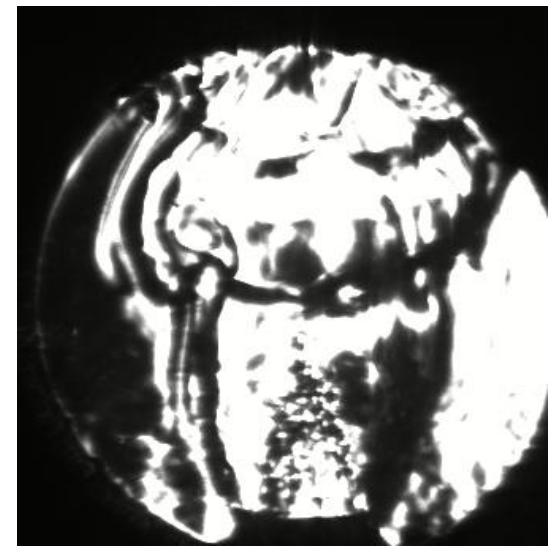

$\mathrm{P}=0.3 \mathrm{MPa}$

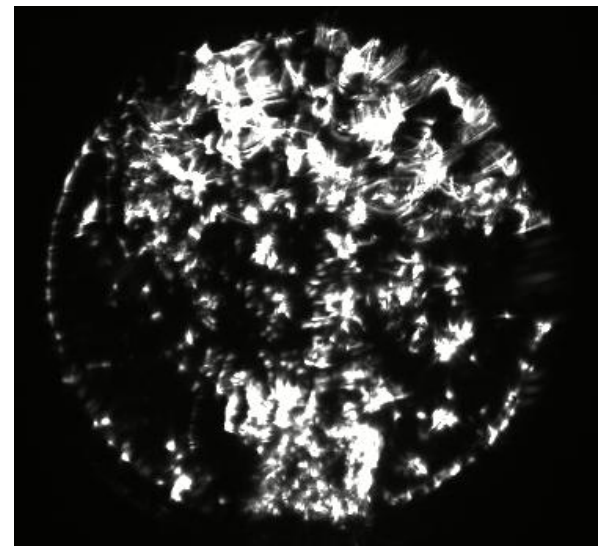

$\mathrm{P}=0.7 \mathrm{MPa}$

Fig. 4 Instantaneous images under different pressures

To commission the schlieren apparatus, the system was operated at atmospheric conditions, with all the elements of flash-lamp source, pinhole, mirrors, lens, knife edge, filter, and camera to assess any degradation in image quality arising from the windows.

Some experimentation with knife-edge was required to achieve good image quality and the photographs show a change in knife-edge position.

Schlieren images from the elevated pressure experiments illustrate the difficulty of data manipulation to arrive at flame speed. Although the flame is stable, there is sufficient shot-to-shot variation to give a fuzzy appearance to the averaged image and binary image extraction was necessary to provide a consistent density gradient interpretation.

Good schlieren images were obtained after some tuning. The effects of flame radiation were controlled using a filter in front of the camera lens and short camera shutter duration $(1 \mathrm{~ms})$. Using the filter preserved the dynamic range of the $\mathrm{CCD}$, thus reducing errors due to saturation.

The short shutter speed minimized image blurring from flame oscillation in space. The flash lamp frequency was set to be $100 \mathrm{~Hz}$, and the trigger was set synchronously for the camera and the lamp giving clear,sharp images The original instantaneous images were taken from the CCD at 256 grey scales, and an averaged image was determined by an average of pixel data taken from fifty images. A program was written to find the digital profile of flame front mainly according to the brightness of the edge, assuming axisymmetry of the flame. In the program, the flame zone was firstly chosen from the averaged image, the threshold value was determined considering the intensity histogram and average pixel data for each scan line.

The number of images taken-for the results in the paper is 50 , however, more images were used in development (in increments up to 300), and no obvious difference was found between these cases, this might because of the relatively sharp difference between the background and the flame image. Furthermore, turbulence generator, nozzle configuration, stabilized diffuse flame and chamber volume were carefully designed to minimize the perturbation (shear flow) caused by the edge of the nozzle and outside flow together with the heat loss.

The illustration shows the development of a typical schlieren record from a single instantaneous image to a 50-image average and its derived intensity profile for conditions of $\varnothing=0.9$ at $700 \mathrm{kPa}$ chamber pressure. 


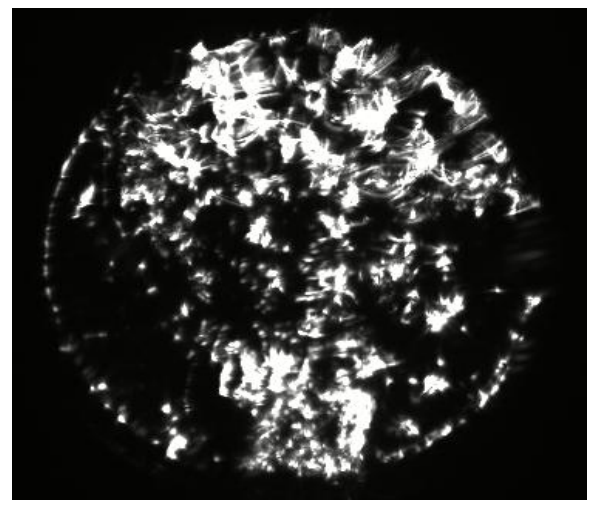

Instantaneous Image

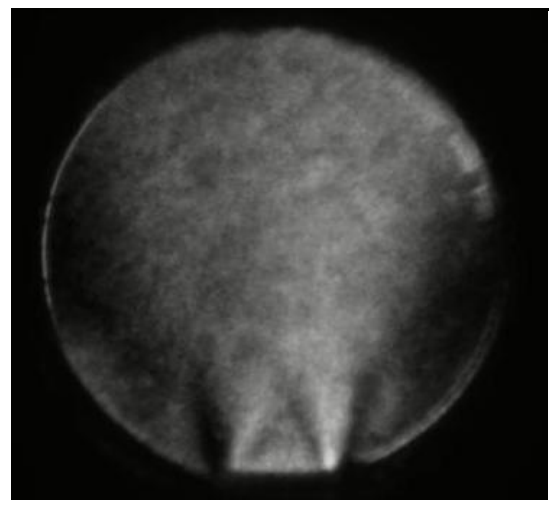

Averaged Image

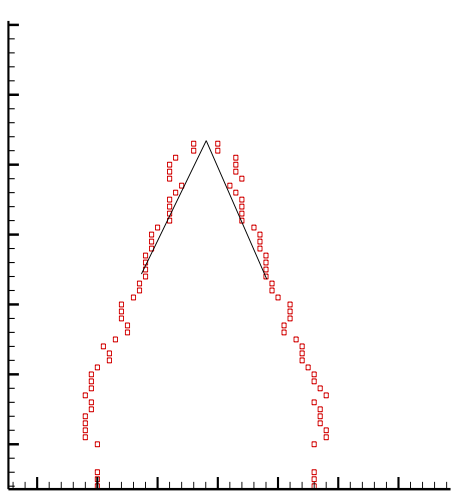

Digital Profile

Fig. 5 Illustration for image processing

Instantaneous and averaged schlieren images, with derived flame envelope over a range of conditions were taken. There are significant variations in image quality and derived flame vertex angle over the pressure range covered, as shown, Figs $4 \& 5$.

The main experimental results were obtained with an equivalence ratio of 0.9 and at pressures up to $0.8 \mathrm{MPa}$, the experimental details and conditions are shown below.

\begin{tabular}{|l|l|l|l|l|l|l|l|l|l|l|l|l|l|}
\hline $\begin{array}{l}\mathrm{P} \\
(\mathrm{KPa})\end{array}$ & $\begin{array}{l}\mathrm{T} \\
(\mathrm{K})\end{array}$ & $\begin{array}{l}\mathrm{V} \\
(\mathrm{m} / \mathrm{s})\end{array}$ & $\begin{array}{l}\mathrm{u}^{\prime} \\
(\mathrm{m} / \mathrm{s})\end{array}$ & $\mathrm{Re}_{\mathrm{T}}$ & $\begin{array}{l}\mathrm{S}_{\mathrm{L}} \\
(\mathrm{m} / \mathrm{s})\end{array}$ & $\begin{array}{l}\delta \\
(\mathrm{mm})\end{array}$ & $\begin{array}{l}\mathrm{It} \\
(\mathrm{mm})\end{array}$ & $\begin{array}{l}\lambda \\
(\mathrm{mm})\end{array}$ & $\begin{array}{l}\eta \\
(\mathrm{mm})\end{array}$ & $\mathrm{Le}$ & $\mathrm{Da}$ & $\mathrm{Ka}$ & $\mathrm{u}^{\prime} / \mathrm{SL}$ \\
\hline 100 & 300 & 3.75 & 0.29 & 40.95 & 0.34 & 0.064 & 3.09 & 0.48 & 0.190 & 0.92 & 56 & 0.113 & 0.85 \\
\hline 230 & 296 & 1.39 & 0.12 & 23.29 & 0.24 & 0.039 & 2.82 & 0.47 & 0.192 & 0.92 & 146 & 0.041 & 0.49 \\
\hline 300 & 296 & 1.06 & 0.10 & 38.24 & 0.21 & 0.045 & 2.83 & 0.53 & 0.229 & 0.92 & 137 & 0.039 & 0.46 \\
\hline 400 & 343 & 1.16 & 0.11 & 61.39 & 0.24 & 0.029 & 3.83 & 0.49 & 0.174 & 0.93 & 281 & 0.028 & 0.47 \\
\hline 600 & 329 & 1.06 & 0.08 & 57.81 & 0.25 & 0.017 & 3.08 & 0.41 & 0.147 & 0.93 & 534 & 0.014 & 0.33 \\
\hline 700 & 354 & 1.06 & 0.09 & 67.07 & 0.20 & 0.022 & 3.20 & 0.39 & 0.136 & 0.94 & 326 & 0.025 & 0.45 \\
\hline 760 & 357 & 1.09 & 0.09 & 79.67 & 0.19 & 0.021 & 3.64 & 0.41 & 0.136 & 0.94 & 386 & 0.023 & 0.45 \\
\hline
\end{tabular}

Table 1 Tabulated Experimental Conditions and Results

Where: $\mathrm{P}=$ mixture pressure; $\mathrm{T}=$ mixture temperature; $\mathrm{V}=$ nozzle velocity;

$\mathrm{u}^{\prime}$ = fluctuating velocity; $\operatorname{Re}_{\mathrm{T}}\left(\mathrm{u}^{\prime} \mathrm{t} t / \delta / \mathrm{S}_{\mathrm{L}}\right)=$ nozzle Reynolds $\mathrm{N}^{\mathrm{o}}$;

$\mathrm{S}_{\mathrm{L}}=$ laminar flame speed calculated from CHEMKIN;

$\delta=$ flame thickness $=\left(\lambda_{\mathrm{u}} /\left(\rho_{\mathrm{u}} \mathrm{Cp}_{\mathrm{u}} \mathrm{S}_{\mathrm{L}}\right)\right.$ (for u: unburnt conditions); It = Integral length scale;

$\lambda=\left(1 \mathrm{t}^{2} / \operatorname{Re}_{\mathrm{T}}\right)^{1 / 2}=$ Taylor scale; $\eta\left(1 \mathrm{t} / \mathrm{Re}_{\mathrm{T}}{ }^{3 / 4}\right)=$ Kolmogoroff scale;

$\mathrm{Da}\left(1 \mathrm{t} \mathrm{S}_{\mathrm{L}} / \delta / \mathrm{u}^{\prime}\right)=$ Damköhler $\mathrm{N}^{\mathrm{o}} ; \mathrm{Ka}\left(\operatorname{Re}_{\mathrm{T}}^{-1 / 2}\left(\mathrm{u}^{\prime} / \mathrm{S}_{\mathrm{L}}\right)^{2}\right)=$ Karlovitz $\mathrm{N}^{\mathrm{o}}$

Ruhr Gas was used for the experiment, which contains significant amounts of ballast and higher hydrocarbons.

\begin{tabular}{|l|l|}
\hline Mixture Component & Mol (\%) \\
\hline Carbon dioxide (CO2) & 1.57 \\
\hline Nitrogen (N2) & 8.74 \\
\hline Methane (CH4) & 86.45 \\
\hline Ethane $(\mathrm{C} 2 \mathrm{H} 6)$ & 2.55 \\
\hline Propane $(\mathrm{C} 3 \mathrm{H} 8)$ & 0.69 \\
\hline
\end{tabular}

Table 2 The fuel mixture (Ruhr gas) composition 
Pilot fuel mass flows were $\sim 0.5-1.5 \%$ of main fuel flow: equivalence ratio was calculated on total fuel flow.

The laminar burning velocity $\mathrm{S}_{\mathrm{L}}$ was calculated from the program package CHEMKIN, the chemical kinetics was modelled by GRI-MECH v3.0.

\section{Discussions}

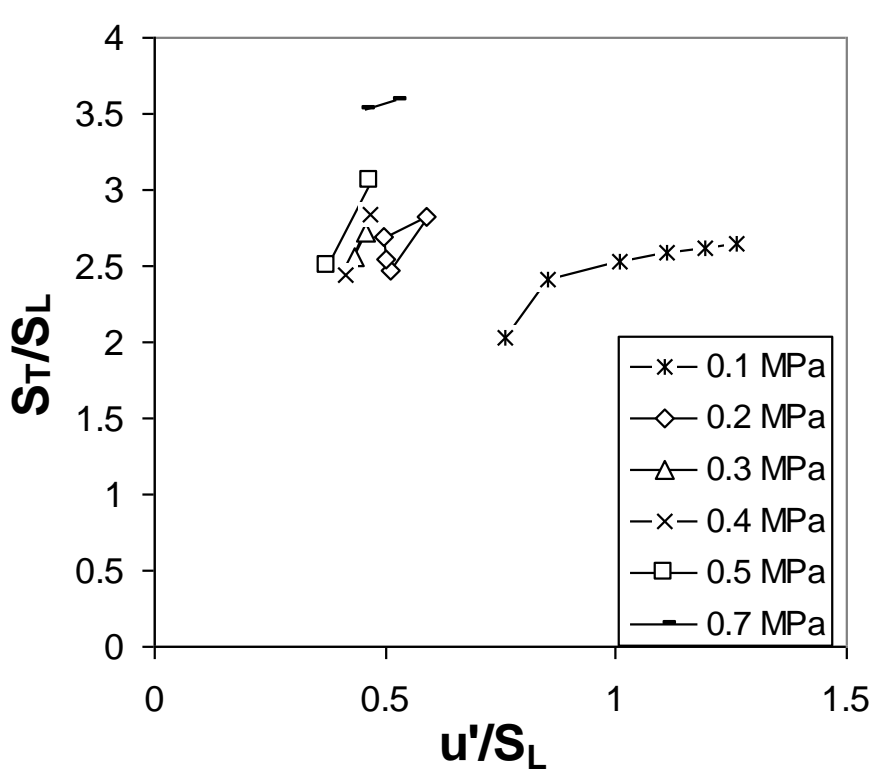

Fig. 6 Relationship between $S_{T} / S_{L}$ and $u ' / S_{L}$ for various chamber pressures

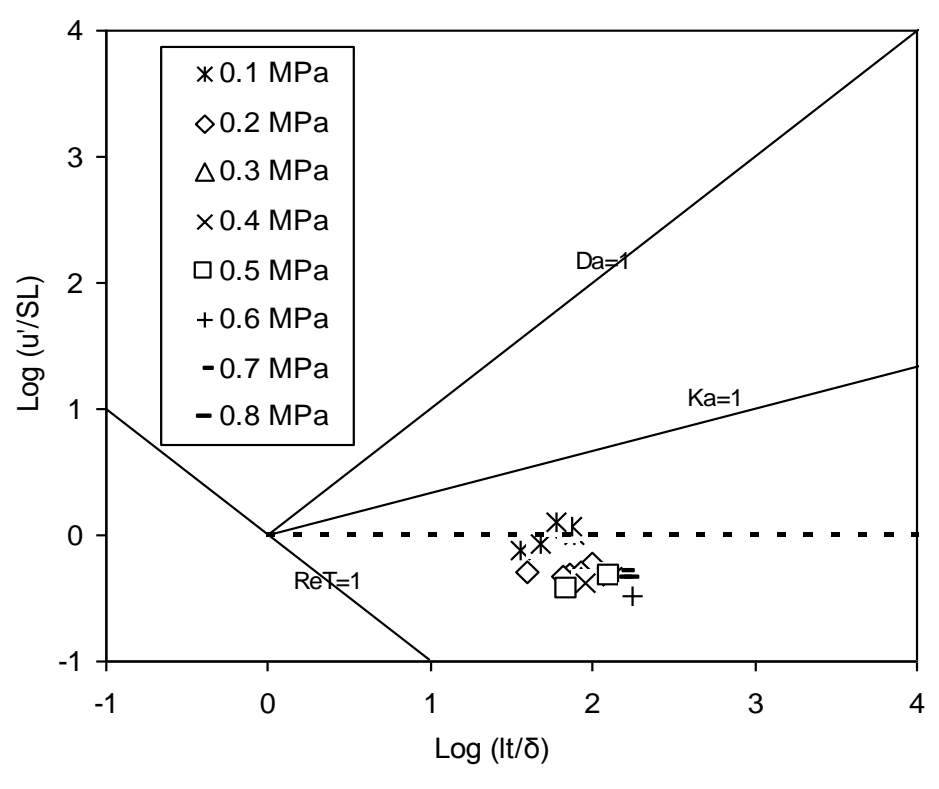

Fig. 7 Turbulent combustion regimes of the investigated flames

From Fig. 6, we can see the asymptotic tendency under 0.1 and $0.2 \mathrm{MPa}$ similar with [7], however it is not clear due to the lack of data under higher pressures. The effects of pressure on $\mathrm{S}_{\mathrm{T}} / \mathrm{S}_{\mathrm{L}}$ are significant, this implies an additional pressure modification term may be helpful when generating a correlation between $\mathrm{S}_{\mathrm{T}} / \mathrm{S}_{\mathrm{L}}$ and $\mathrm{u}$ '/ $\mathrm{S}_{\mathrm{L}}$.

The turbulent flames for the experimental conditions are mostly in the wrinkled-flamelets regimes of Bray's diagram [8] as shown in Fig. 7. 


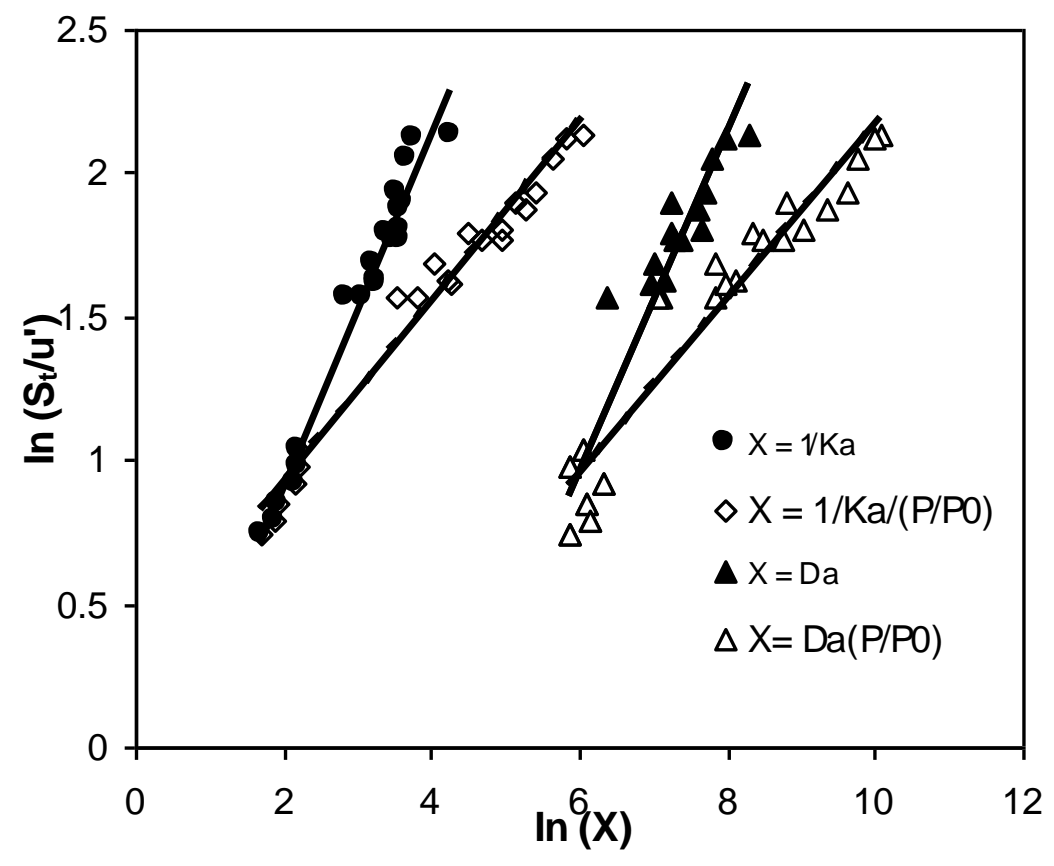

Fig. 8 Relationship between $S_{T} / u^{\prime}$ and Ka, Da

There are many proposed correlations as to the relationship between turbulent burning velocity, turbulent intensity, timescale, laminar burning velocity and so on and these correlations are summarized in references [9-11].

Our experimental data Fig. 8, shows a substantially stronger dependence of $\mathrm{S}_{\mathrm{T}} / \mathrm{u}$ ' both on Da and $\mathrm{Ka}\left(\mathrm{S}_{\mathrm{T}} \sim \mathrm{u}^{\prime}(\mathrm{Da})^{0.59}, \mathrm{~S}_{\mathrm{T}} \sim \mathrm{u}^{\prime}(\mathrm{Ka})^{-0.61}\right)$ than other datacases [12-13] where $\mathrm{S}_{\mathrm{T}} \sim \mathrm{u}^{\prime}(\mathrm{Da})^{0.27}$ and $\mathrm{S}_{\mathrm{T}} \sim$ $\mathrm{u}^{\prime}(\mathrm{Ka})^{-0.3}$. However the features of our experimental data basically agree with their correlations when a pressure modification item $\left(\mathrm{P} / \mathrm{P}_{0}\right)$ item is added, here $\mathrm{P}_{0}$ is the atmosphere pressure, 0.1 $\mathrm{MPa}$.

$\mathrm{S}_{\mathrm{T}} \sim \mathrm{u}^{\prime}\left[\left(\mathrm{Da}\left(\mathrm{P} / \mathrm{P}_{0}\right)\right]^{0.30}, \mathrm{~S}_{\mathrm{T}} \sim \mathrm{u}^{\prime}\left[1 / \mathrm{Ka} /\left(\mathrm{P} / \mathrm{P}_{0}\right)\right]^{-0.31}\right.$

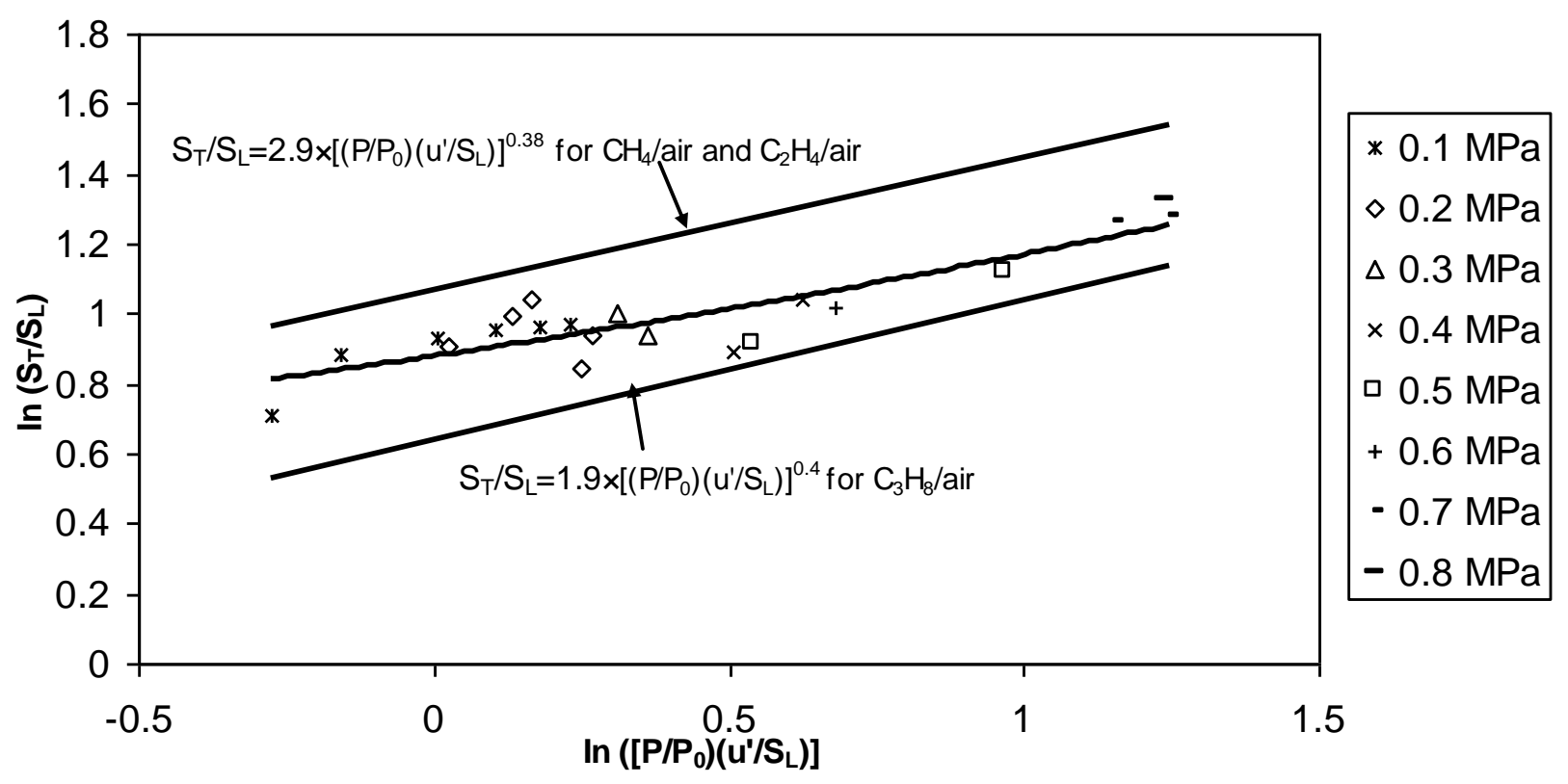


The turbulent velocity data in Fig.9 are within the range of other correlations reflecting the composition of the fuel used in the experiment [12], when considering about the $u^{\prime}$ and $S_{L}$.

The correlation obtained from this work is:

$\mathrm{S}_{\mathrm{T}} / \mathrm{S}_{\mathrm{L}}=2.4 \times\left[\left(\mathrm{P} / \mathrm{P}_{0}\right)\left(\mathrm{u}^{\prime} / \mathrm{S}_{\mathrm{L}}\right)\right]^{0.30}$

The differences in coefficients are due to the different compositions.

Furthermore, unlike in the reference [12], different mixture temperatures were tested during this work, this also brings some effects apart from the pressure. Correlations were obtained by adding two different terms $\left(\mathrm{T}_{0} / \mathrm{T}\right)$ and $\left(\mathrm{T} / \mathrm{T}_{0}\right)$, here $\mathrm{T}_{0}$ is equal to $273.15 \mathrm{~K}$.

$\mathrm{S}_{\mathrm{T}} / \mathrm{S}_{\mathrm{L}}=2.5 \times\left[\left(\mathrm{P} / \mathrm{P}_{0}\right)\left(\mathrm{u}^{\prime} / \mathrm{S}_{\mathrm{L}}\right)\left(\mathrm{T}_{0} / \mathrm{T}\right)\right]^{0.34}$

$\mathrm{S}_{\mathrm{T}} / \mathrm{S}_{\mathrm{L}}=2.3 \times\left[\left(\mathrm{P} / \mathrm{P}_{0}\right)\left(\mathrm{u}^{\prime} / \mathrm{S}_{\mathrm{L}}\right)\left(\mathrm{T} / \mathrm{T}_{0}\right)\right]^{0.26}$

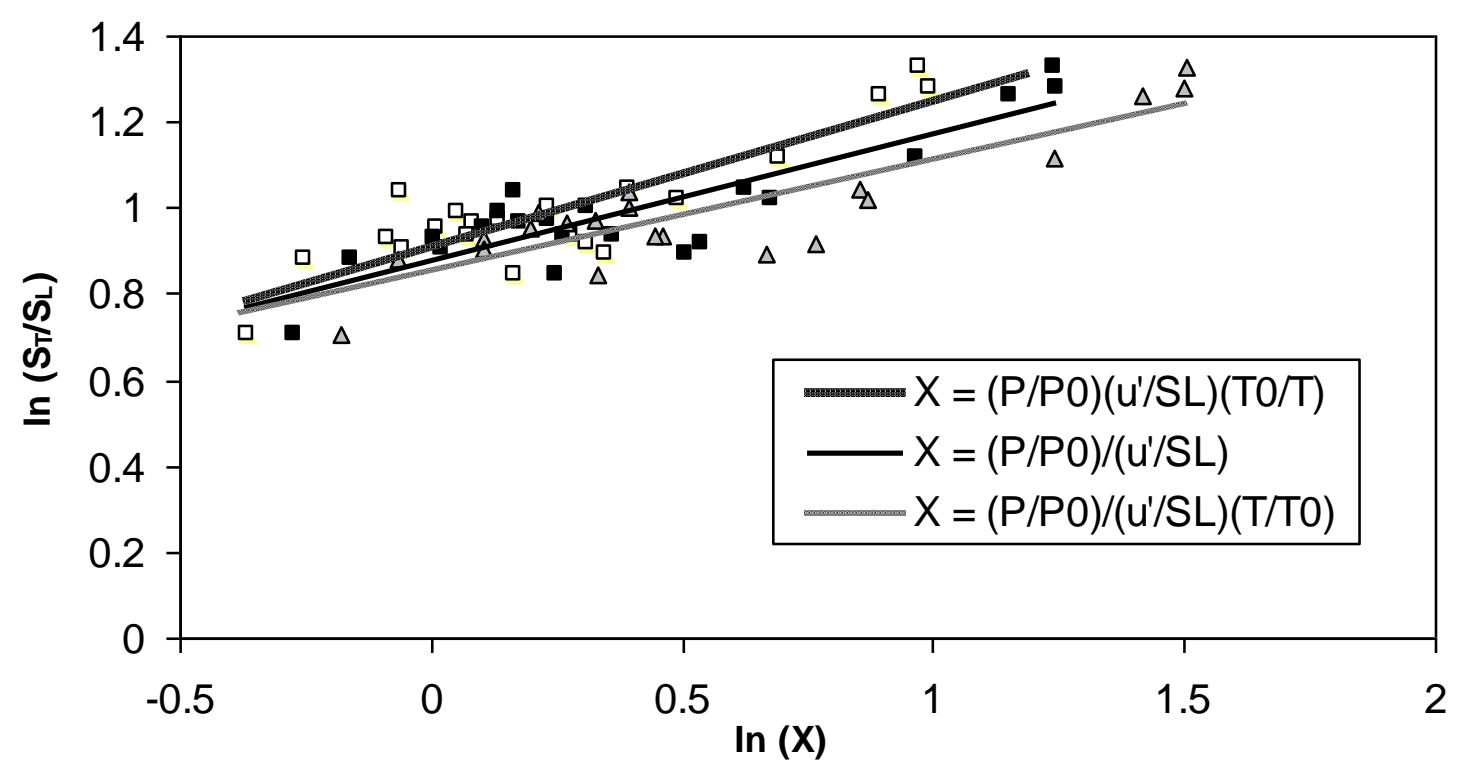

Fig. 10 General correlation of turbulent burning velocity

Different temperature cases have been investigated during the experiment, however this will not impact as much as pressure on the turbulent flame speed. When adding the term $\left(\mathrm{T} / \mathrm{T}_{0}\right)$, the exponent is nearer to the value given in [14], this may imply the temperature acts inversely to the pressure, Fig 10.

\section{Conclusions}

In this work, turbulent flame speeds $\mathrm{S}_{\mathrm{T}}$ were measured over a range of pressures to $0.8 \mathrm{MPa}$ using a jet-flow apparatus fired with a synthetic mixture representing a mid-European natural gas. The gas contained significant proportions of ballast gases and higher hydrocarbons which affect the turbulent velocity.

The following results are obtained:

An asymptotic tendency of the $S_{T} / S_{L}$ curves with increasing $u^{\prime} / S_{L}$ was seen, although this is not entirely clear due to the reduced data set available under high pressures. 
A power law of $\mathrm{S}_{\mathrm{T}} / \mathrm{S}_{\mathrm{L}}$ with $\left(\mathrm{P} / \mathrm{P}_{0}\right)\left(\mathrm{u}^{\prime} / \mathrm{S}_{\mathrm{L}}\right)$ was obtained using the vertex angle from the mean flame cone by schlieren imaging, which shows comparable agreement with other authors [12].

Also as $\mathrm{S}_{\mathrm{T}}$ correlates to Damköhler and Karlovitz number, a pressure modification term $\left(\mathrm{P} / \mathrm{P}_{0}\right)^{\mathrm{n}}$ may be helpful to get better correlations.

Further work should be carried to study the high turbulence velocity and the pressure and temperature modification items $\left(\mathrm{P} / \mathrm{P}_{0}, \mathrm{~T} / \mathrm{T}_{0}\right)$ in the correlations.

\section{Acknowledgments}

The flame speed work formed part of a European Commission Framework V project, completed under EC Contract No. ENK5-CT-2000-00060.

\section{References}

1. H. Kobayashi, "Burning Velocity of Turbulent Premixed Flames in a High-Pressure Environment", Twenty-sixth Symposium (International) on Combustion, 1996, pp.389-396

2. H. Kobayashi, "Turbulent Measurements and Observations of Turbulent Premixed Flames at Elevated pressures up to 3.0 MPa", Combustion and Flame, 108: pp. 104-117 (1997)

3. A. Soika, F. Dinkelacker, A. Leipertz, "Pressure influence on the flame front curvature of turbulent premixed flames: comparison between experiment and theory", Combustion and Flame, 132 (3) 2003, pp. 451-462

4. T. Lachaux, F. Halter, C. Chauvean, I. Gokalp and I.G. Shepherd, "Flame front analysis of high-pressure turbulent lean premixed methane-air flames”, Proceedings of the Combustion Institute, Volume 30, Issue 1, January 2005, pp. 819-826

5. E.M. Laws, "Flow conditioning-A new development", Flow Meas. Instrum. Vol 1 April 1990, pp. 165-170

6. L.W. Kostuik, R.K. Cheng, "Imaging of premixed flames in microgravity", Experiments in Fluids 18 (1994) pp. $59-68$

7. H. Kobayashi, T. Tamura, K. Maruta, T. Niioka, F. A. Williams, "Burning velocity of turbulent premixed flames in a high-pressure environment", Proc. Combust. Inst. 26 (1996) pp. 389-396

8. K.N.C. Bray, in: P.A. Libby, F.A. Williams (Eds.), Turbulent Reacting Flows, Springer-Verlag, Berlin, 1980

9. O.L. Gülder, Turbulent premixed flame propagation models for different combustion regimes, Proc. Combust. Inst. 23 (1990) pp. 743-750

10. A. Linăn, F.A. Williams, Fundamental Aspects of Combustion, Oxford University Press, Cambridge, 1993, pp. 119-132

11. A.N. Lipatnikov, J. Chomiak, "Turbulent flame speed and thickness: phenomenology, evaluation, and application in multi-dimensional simulations", Progress in Energy and Combustion Science 28 (2002) pp. 1-74

12. V.P.Karpoc, E.S. Severin, Combustion, Explosion, and Shock Waves, Vol 16, 1980, pp41

13. D. Bradley, A.K.C. Lau, M. Lawes, Philosophical Transactions of the Royal Society of London A (1992), pp.338359

14. H. Kobayashi, "Experimental study of high-pressure turbulent premixed flames", Experimental Thermal and Fluid Science 26 (2002) pp. 375-387 